\title{
Transboundary Spread of Brucella canis through Import of Infected Dogs, the Netherlands, November 2016-December 2018
}

Marloes A.M. van Dijk, Marc Y. Engelsma, Vanessa X.N. Visser, Ingrid Keur, Marjolijn E. Holtslag, Nicole Willems, Björn P. Meij, Peter T.J. Willemsen, Jaap A. Wagenaar, Hendrik I.J. Roest, ${ }^{1}$ Els M. Broens ${ }^{1}$

Brucella canis had not been isolated in the Netherlands until November 2016, when it was isolated from a dog imported from Romania. Including this case, 16 suspected cases were notified to the authorities during the following 25 months. Of these 16 dogs, 10 were seropositive; tracking investigations found another 8 seropositive littermates. All seropositive animals were rescue dogs imported from Eastern Europe. B. canis was cultured from urine, blood, and other specimens collected from the dogs. Genotyping of isolates revealed clustering by litter and country. Isolating $B$. canis in urine indicates that shedding should be considered when assessing the risk for zoonotic transmission. This case series proves introduction of $B$. canis into a country to which it is not endemic through import of infected dogs from $B$. canis-endemic areas, posing a threat to the naive autochthonous dog population and humans.

Cani anine brucellosis is caused by the bacterium Brucella canis. Reproductive disorders such as late abortion, stillbirth, epididymitis, and sperm anomalies are most frequently observed (1). Other clinical signs are lymphadenitis $(1,2)$ and musculoskeletal disease (e.g., discospondylitis) (3). In addition, the infection can remain subclinical (2). B. canis is mostly transmitted vertically from bitch to offspring or

Author affiliations: Utrecht University Faculty of Veterinary Medicine, Utrecht, the Netherlands (M.A.M. van Dijk, N. Willems, B.P. Meij, J.A. Wagenaar, E.M. Broens); Wageningen Bioveterinary Research, Lelystad, the Netherlands (M.Y. Engelsma, M.E. Holtslag, P.T.J. Willemsen, J.A. Wagenaar, H.I.J. Roest); Netherlands Food and Consumer Product Safety Authority, Utrecht (V.X.N. Visser, I. Keur); Ministry of Agriculture, Nature and Food Quality, The Hague, the Netherlands (H.I.J. Roest)

DOI: https://doi.org/10.3201/eid2707.201238 venereally through vaginal discharge and semen; urine has also been implicated as a possible mode of transmission $(1,4,5)$.

B. canis is a zoonotic pathogen; humans can become infected through direct contact with secreta and excreta of infected dogs $(6,7)$ or through laboratory exposure $(8,9)$. Clinical signs in humans vary from subclinical infection (10) to fever, malaise, splenomegaly, and lymphadenopathy (7). Human cases of $B$. canis infection are reported infrequently. However, the prevalence of human $B$. canis infections is probably underestimated; the diagnosis might be missed because of nonspecific clinical signs and the absence of accurate serologic tests for B. canis antibodies in humans $(6,11)$. In the United States, a seroprevalence of $3.6 \%$ was found among persons occupationally exposed to dogs. Two seropositive persons had clinical symptoms of brucellosis, and both reported contact with $B$. canis-seropositive dogs (10). In addition, an outbreak involving 6 seropositive persons, 5 of whom had clinical symptoms, was described after contact with a seropositive litter (6). In general, B. canis appears to cause less severe clinical symptoms in humans than other Brucella spp. (12). However, the public health relevance of B. canis needs further investigation before a proper risk assessment can be performed.

$B$. canis is considered endemic in the southern United States, Central America, and South America and has been reported from Canada, Asia, Africa, and Europe $(7,13)$. Sporadic cases originating from northwestern Europe have been reported and were at least partially caused by importing an infected dog $(13,14)$. Recent papers have expressed concerns about the introduction of $B$. canis in countries to which it is not

${ }^{1}$ These senior authors contributed equally to this article. 
endemic through infected dogs $(15,16)$. Brucellosis in dogs is, in contrast to livestock, not notifiable to the World Organisation for Animal Health (OIE) or the European Union (EU directive 64/432/EEG). In the Netherlands, brucellosis is notifiable in humans and all mammal species $(17,18)$. B. canis had not been isolated in the Netherlands until November 2016, when it was isolated from a dog imported from Romania that had discospondylitis. Raised awareness following this first case resulted in multiple notifications at the Incidence Crisis Centre (NVIC) of the Netherlands Food and Consumer Product Safety Authority (NVWA). This study describes the follow-up of these notifications and the implications for animal and human health.

\section{Methods}

\section{Notifications and Study Period}

Animal owners, veterinarians, and laboratories in the Netherlands are obliged to notify suspicions of brucellosis to the competent authority, the NVWA, according to Dutch legislation $(17,18)$. Suspicions are mostly based on clinical signs compatible with brucellosis and a history of importation. In this study, we include all notified and related B. canis cases during November 2016-December 2018, provided there was a clinical suspicion (e.g., routine tests for export or import excluded), and diagnostic tests were performed at the National Reference Laboratory (NRL; Wageningen Bioveterinary Research, Lelystad, the Netherlands). No mandatory control measures for pets are in place once a positive case has been identified.

\section{Tracking Investigations}

Upon notification, NVIC began investigations to track potential transmission by taking samples from suspected dogs and (if applicable) contact dogs or littermates for serologic and bacteriologic (blood and urine) evaluation. Contact dogs were defined as any dog imported with, cohabiting with, or regularly spending time with the suspected dog. Dogs were considered positive if they tested positive for B. canis antibodies or when the bacterium was cultured from blood, urine, or infection sites. In case of euthanasia of a seropositive dog, postmortem examination was performed by the NRL, and samples of various tissues were collected for culture. Diagnostic tests were performed by the NRL.

\section{Detection of $B$. canis Antibodies}

Serum samples were tested for B. canis-specific antibodies by the 2-Mercapto-ethanol serum agglutination test as described by Alton et al. (19) as reference method with an in-house derived positive rabbit anti-B. $c a-$ nis control serum (NRL in-house validation). Interpretation of the antibody titer is $<1: 50$ negative, 1:50-1:100 inconclusive, $\geq 1: 200$ positive (19).

\section{Detection of $B$. canis}

\section{Culture}

We isolated Brucella spp. from clinical and tissue samples according to the OIE protocol (20). All laboratory work with potential Brucella-contaminated samples was performed within a Biosafety Level (BSL) 3 facility. Suspected colonies were confirmed as Brucella spp. by matrix-assisted laser desorption/ionization time-of-flight mass spectrometry on the Bruker MALDI Biotyper (Bruker, https:/ / www.bruker.com) by using an extended in-house Brucella spp. database (21) and PCR.

\section{DNA Isolation, PCR, and Genotyping}

DNA from tissue samples was extracted by using the DNeasy Blood and Tissue Kit (QIAGEN, https:// www.qiagen.com). DNA isolation from Brucellasuspected colonies was performed by suspending the colony in $200 \mu \mathrm{L}$ nuclease-free water (Sigma-Aldrich, https://www.sigmaaldrich.com) and boiling at $100^{\circ} \mathrm{C}$ for $8 \mathrm{~min}$, followed by centrifugation for 2 $\min$ at $20,000 \times g$. We performed real-time PCR targeting the IS711 sequences of Brucella spp. (22). Colonies and tissue samples were considered positive after real-time PCR if the results showed a cycle threshold $\left(C_{t}\right)$ value of $\leq 36$ (with sigmoid curve), inconclusive if $C_{t}$ value was $>36$ but $<40$ (with inconclusive sigmoid curve), and negative if $C_{t}$ value was $\geq 40$ or there was no $C_{t}$ at all.

For in silico multiple-locus variable number tandem repeat analysis (MLVA) and multilocus sequence typing (MLST), we constructed fragmented libraries by using Nextera DNA sample preparation kit (Illumina, https:/ / www.illumina.com), as earlier published (21). Next generation whole-genome sequencing was performed by paired-end sequencing (300-bp reads) by using the Illumina technology on the MiSeq instrument (Illumina). We performed de novo assembly of the quality filtered reads by using ABySS-pe version 1.3.3 (23). Reads were aligned by using Bowtie2 version 0.2 (http:/ / bowtie-bio.sourceforge.net/bowtie2/index.shtml) to the assembled contigs and the contig sequences were manually verified by using Tablet version 14.04 .10 (24). We performed in silico MLVA-16 clustering according to the algorithm as described previously (25) by using 
Bionumerics version 7.6 (Applied Maths, https:// www.applied-maths.com) and assigning MLVA-type from DNA-sequence with software (26) or manually. MLST typing was performed in silico with a set of MLST specific primers (27) and the assembled contigs as input, by using the PubMLST.org database (28). For the analysis of $B$. canis genotypes, we compared them to genotypes from the publicly available database MLVA bank (26). Of note, the background of reference genotypes is unknown (e.g., import history of the dogs); therefore, these genotypes might not originate from the country in which they were isolated. If $>1$ isolate was recovered from different materials or time points from a dog in our study, 1 isolate per time point was sequenced with $\leq 2$ isolates per dog to assess carriage of different genotypes $(29,30)$.

\section{Results}

Including the first case of canine brucellosis in the Netherlands, 16 suspected cases were notified to NVIC in the study period (Table 1). The reasons for notification are variable: 7 dogs had a seropositive test result at the NRL, 7 dogs had a clinical complaint compatible with $B$. canis infection, and 2 cases had a B. canis-seropositive culture (Table 1). Of the 16 dogs,
15 had a history of importation. A total of 10 tested seropositive at the NRL, 4 tested seronegative, and 2 had an inconclusive antibody titer initially but were considered negative during follow-up (retesting after $\geq 3$ weeks) (Table 1). The 10 seropositive dogs (hereafter referred to as notified seropositive cases) had been imported into the Netherlands 2-32 (median 9) months before notification. Tracking investigations into the 10 notified seropositive cases identified 11 littermates and 13 other contact dogs (Table 1). Of the 11 littermates, 8 were tested by the NRL and all $(8 / 8)$ were seropositive. Of the 13 contact dogs, 6 were tested by the NRL; 5 were seronegative and 1 had an inconclusive titer (1:50). This dog lived together with notified case dog \#12; they had shared an enclosure for 1.5 years with another seronegative contact $\operatorname{dog}(<1: 50)$. The dog was euthanized because of geriatric health issues and was thus lost to followup. Thus, the total number of seropositive cases in this study was 18 (10 notified seropositive cases and 8 littermates) (Table 2, https://wwwnc.cdc.gov/EID/ article/27/7/20-1238-T2.htm).

Of these 18 dogs, 14 (78\%) had musculoskeletal disease with such clinical signs as lameness and neck or back pain; discospondylitis was diagnosed in 11 .

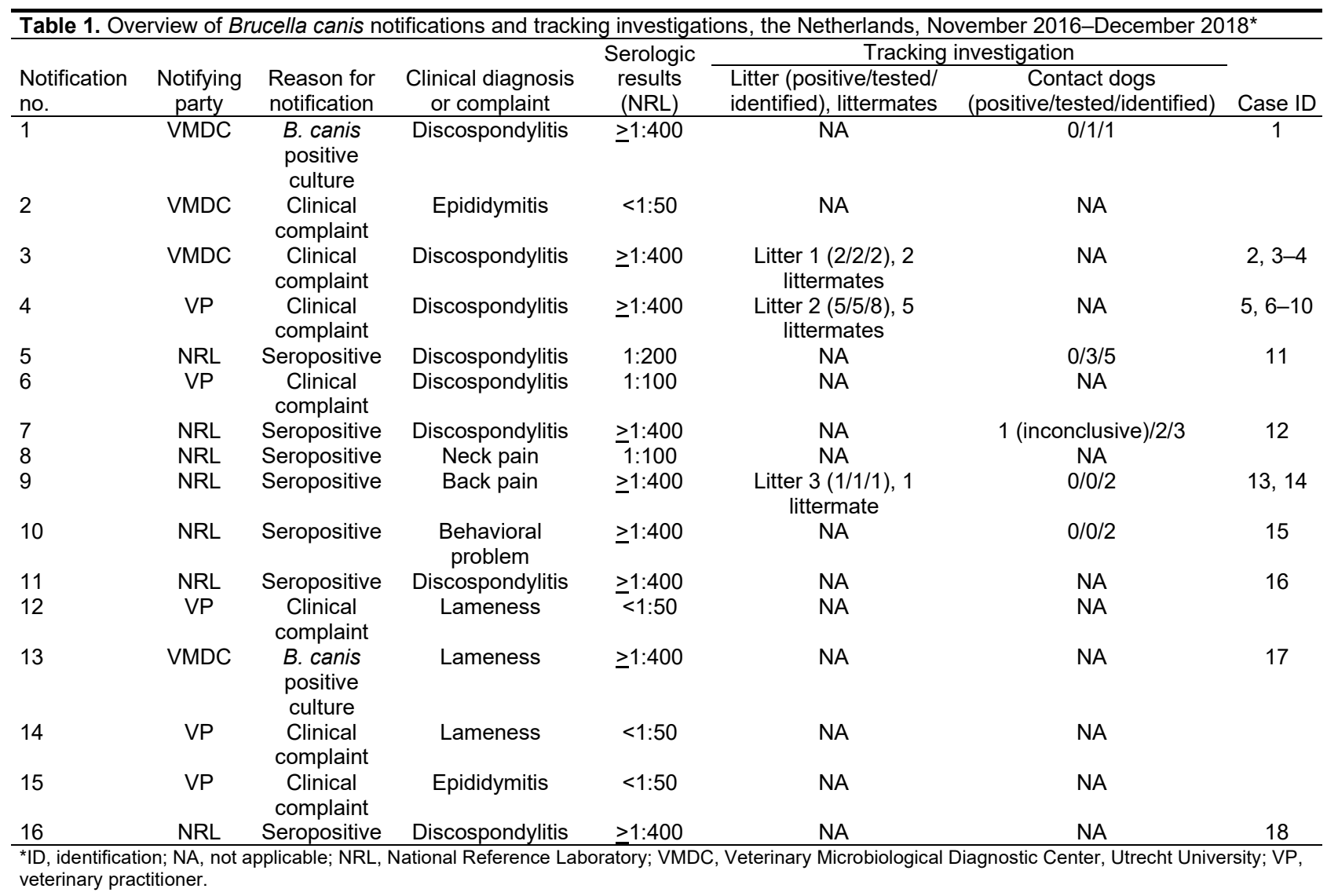


Information regarding onset of clinical signs was available for 7 of these 13 dogs and occurred $0-3$ months after import. One dog had a behavioral problem and 3, all littermates identified through tracking investigations, showed no clinical signs.

All dogs were mixed-breed rescue dogs imported from Romania $(n=7)$, Bulgaria $(n=10)$ and Croatia ( $=1$ ). Among them were 9 female dogs, of which 7 were neutered, and 9 male dogs, of which 8 were neutered.

We collected blood, urine, or samples from the infection site from 16 of 18 seropositive dogs for culture; 10 dogs tested positive on these clinical samples (Table 2). Three dogs (nos. 3, 9, and 17) were euthanized because of deteriorating clinical symptoms linked to brucellosis; postmortem examination and cultures revealed growth of $B$. canis in collected tissue samples in 2 of 3 dogs (Table 2). This brings the total number of culture-positive cases in this study to 11 (10 from clinical samples and 1 exclusively from postmortem tissue samples) (Table 2). We cultured isolates from blood (6 samples), urine (5 samples), lymph nodes (3 samples), spleen (2 samples), lung (1 sample), synovial fluid (1 sample), and intervertebral disc (1 sample) (Table 2 ).

Genotyping was performed for 14 isolates; from 3 dogs, >1 isolate was recovered at different time points. Genotyping of isolates confirmed a close relation between isolates from the same litter (Figure, https: / / wwwnc.cdc.gov/EID/article/27/7/201238-F1.htm). Isolates from dogs imported from Bulgaria show high similarity. Isolates from litter $3 \mathrm{im}-$ ported from Romania show high similarity, and the isolate from $\operatorname{dog} \# 3$ clusters with a reference strain from Romania. Only the isolate from $\operatorname{dog} 1$ does not cluster with any other (reference) strain from Romania. On the basis of in silico MLVA-16 analyses, the 2 isolates from dog 5 (samples taken with a 12-month interval) showed no difference in loci. The 2 isolates from dog 9 (3-month interval) showed 1 locus difference (MLVA Bruce16: first isolate 7 repeats, second 8 repeats). The 2 isolates from $\operatorname{dog} 8$ (6-month interval) showed 2 loci difference (MLVA Bruce09: first isolate 7 repeats, second 6 repeats; Bruce16: first isolate 8 repeats, second 9 repeats).

\section{Discussion}

Brucellosis in dogs is not notifiable to the OIE or the European Union; therefore, prevalence data on canine brucellosis in different countries are scarce. Literature does confirm occurrence of $B$. canis in stray dogs in Bulgaria $(31,32)$ and reports bacterial isolates from dogs in Romania $(16,33)$. Buhmann et al. give an overview of test results for $B$. canis on the basis of data from a large laboratory in Europe receiving samples from 20 different countries in Europe. However, the background of the dogs (i.e., country of origin) is unknown, which makes it difficult to assess the risk of importing dogs from specific countries of origin (13).

The Netherlands imports an estimated 21,000 dogs legally per year (unpublished report, NVWA, 2018). According to the TRAde Control and Expert System (TRACES, https://webgate.ec.europa.eu/sanco/traces), a mean of 3,433 (range 2,925-3,950) dogs per year were imported from Romania, 724 (range 557-986) dogs per year from Bulgaria, and 20 (range 9-34) dogs per year from Croatia for the period 2015-2018. This case series underlines the risk of importing dogs from countries to which B. canis is endemic. Because B. canis was never isolated in the Netherlands before and most dogs showed clinical signs of infection shortly after arrival, all cases are considered import cases. This supposition is supported by the analysis of the genotypes, which showed clustering of isolates within litter and country. Minor differences between genotypes ( 1 or 2 loci) were seen in isolates from the same dog or litter, which might be explained by coinfection or withinhost evolution $(29,30)$.

The clustering of isolates within a litter confirms vertical transmission of $B$. canis. The most common transmission route of $B$. canis is venereal. Most dogs in our study $(15 / 18)$ were neutered, which reduced the risk for transmission through genital secretions. Urinary shedding has been implicated as a possible transmission route for dogs cohabiting with male dogs $(4,5)$. Bacteriuria has been demonstrated in both sexes; however, female dogs appear to shed a lower number of bacteria per milliliter (5). Serikawa et al. demonstrated up to $10^{6}$ bacteria/mL urine in male dogs, which supports potential transmission of $B$. $c a-$ nis through urinary shedding (4). To our knowledge, all studies on urinary shedding have been conducted with intact animals. Shedding by neutered dogs is believed to be less likely (34), but evidence to confirm this does not exist. In our case series, shedding of $B$. canis in urine was found in 4/13 (31\%) neutered dogs and $1 / 3(33 \%)$ intact dogs, indicating that shedding by neutered dogs does occur and should be taken into account. Further research into the number of bacteria shed through urine of neutered dogs infected with $B$. canis is warranted to assess the risk for transmission to other animals or humans.

The diagnosis of a B. canis infection in dogs is hampered by subclinical disease and nonspecific clinical signs. In addition, both serologic testing and bacterial isolation have their limitations because of the nature of the disease (34). To avoid spread of canine 
brucellosis, dogs should be tested before international movement (7). This process should involve a combination of tests at different times (34). However, freedom of trade between European Union member states hampers the unilateral introduction of mandatory control measures.

The zoonotic risk associated with the dogs infected with $B$. canis in our case series relates mostly to owners, veterinary personnel, and laboratory technicians. Laboratory personnel were put at risk by the positive cultures of dogs 1 and 17, because routine diagnostic procedures were done under BSL-2 conditions, whereas BSL-3 is mandatory for all Brucella spp. The risk level of the technicians involved was assessed by medical microbiologists of the Municipal Health Service in line with national guidelines (35). To our knowledge, no human infections were linked to the cases documented in this study. However, with the ongoing import of dogs from areas to which $B$. canis is endemic, aspiring dog owners, veterinary personnel, and laboratory technicians will continue to be at risk. Without mandatory testing or control measures, the competent authority in the Netherlands can only inform owners on the poor prognosis and the zoonotic risk and discuss the options of euthanasia or neutering of sexually intact dogs.

In conclusion, this case series proves introduction of $B$. canis in a country to which it is not endemic through import of infected dogs from $B$. canisendemic areas, posing a threat to the naive autochthonous dog population and to humans. The extent of this threat is hard to estimate because of lack of prevalence data and mandatory testing combined with challenges in diagnosing the infection. Furthermore, the case series indicates that shedding of $B$. canis in urine by neutered dogs occurs and should be considered when assessing the risk for transmission.

Surveillance of zoonotic pathogens in companion animals in the Netherlands was funded by the Dutch Ministry of Agriculture, Nature and Food Quality and the Dutch Ministry of Health, Welfare and Sport. Confirmation and laboratory work done at Wageningen Bioveterinary Research was financed by the Ministry of Agriculture, Nature and Food Quality (project no. WOT-01-002-006.01).

\section{About the Author}

Dr. van Dijk is a veterinarian enrolled in a residency program in veterinary microbiology at the Department of Biomolecular Health Sciences, Faculty of Veterinary Medicine, Utrecht University, the Netherlands. She is coordinator of the surveillance program for zoonoses and antimicrobial resistance in companion animals in the Netherlands.

\section{References}

1. Wanke MM. Canine brucellosis. Anim Reprod Sci. 2004; 82-83:195-207. https:// doi.org/10.1016/j.anireprosci.2004. 05.005

2. Keid LB, Chiebao DP, Batinga MCA, Faita T, Diniz JA, Oliveira TMFS, et al. Brucella canis infection in dogs from commercial breeding kennels in Brazil. Transbound Emerg Dis. 2017;64:691-7. https://doi.org/10.1111/tbed.12632

3. Kerwin SC, Lewis DD, Hribernik TN, Partington B, Hosgood G, Eilts BE. Diskospondylitis associated with Brucella canis infection in dogs: 14 cases (1980-1991). J Am Vet Med Assoc. 1992;201:1253-7.

4. Serikawa T, Muraguchi T. Significance of urine in transmission of canine brucellosis. Nippon Juigaku Zasshi. 1979;41:607-16. https:// doi.org/10.1292/jvms1939.41.607

5. Carmichael LE, Joubert JC. Transmission of Brucella canis by contact exposure. Cornell Vet. 1988;78:63-73.

6. Lucero NE, Corazza R, Almuzara MN, Reynes E, Escobar GI, Boeri E, et al. Human Brucella canis outbreak linked to infection in dogs. Epidemiol Infect. 2010;138:280-5. https://doi.org/10.1017/S0950268809990525

7. Hensel ME, Negron M, Arenas-Gamboa AM. Brucellosis in Dogs and Public Health Risk. Emerg Infect Dis. 2018;24:14016. https://doi.org/10.3201/eid2408.171171

8. Marzetti S, Carranza C, Roncallo M, Escobar GI, Lucero NE. Recent trends in human Brucella canis infection. Comp Immunol Microbiol Infect Dis. 2013;36:55-61. https:/ /doi.org/ 10.1016/j.cimid.2012.09.002

9. Dentinger CM, Jacob K, Lee LV, Mendez HA, Chotikanatis K, McDonough PL, et al. Human Brucella canis infection and subsequent laboratory exposures associated with a puppy, New York City, 2012. Zoonoses Public Health. 2015;62:40714. https://doi.org/10.1111/zph.12163

10. Krueger WS, Lucero NE, Brower A, Heil GL, Gray GC. Evidence for unapparent Brucella canis infections among adults with occupational exposure to dogs. Zoonoses Public Health. 2014;61:509-18. https:// doi.org/10.1111/zph.12102

11. Yagupsky P, Morata P, Colmenero JD. Laboratory diagnosis of human brucellosis. Clin Microbiol Rev. 2019;33:e00073-19. https:/ / doi.org/10.1128/CMR.00073-19

12. Glynn MK, Lynn TV. Brucellosis. J Am Vet Med Assoc. 2008;233:900-8. https://doi.org/10.2460/javma.233.6.900

13. Buhmann G, Paul F, Herbst W, Melzer F, Wolf G, Hartmann K, et al. Canine brucellosis: insights into the epidemiologic situation in Europe. Front Vet Sci. 2019;6:151. https:/ / doi.org/10.3389/fvets.2019.00151

14. Holst BS, Löfqvist K, Ernholm L, Eld K, Cedersmyg M, Hallgren G. The first case of Brucella canis in Sweden: background, case report and recommendations from a northern European perspective. Acta Vet Scand. 2012;54:18. https://doi.org/10.1186/1751-0147-54-18

15. Egloff S, Schneeberger M, Gobeli S, Krudewig C, Schmitt S, Reichler IM, et al. Brucella canis infection in a young dog with epididymitis and orchitis. Schweiz Arch Tierheilkd. 2018;160:743-8. https://doi.org/10.17236/sat00190

16. Whatmore AM, Perrett L, Friggens M. Second UK isolation of Brucella canis. Vet Rec. 2017;180:617. https://doi.org/10.1136/vr.j3004

17. Dutch Government Gazette. Animal health and welfare act [in Dutch]. 1992 [cited 2020 Mar 25]. https:/ / wetten.overheid.nl/ BWBR0005662/2019-01-01

18. Dutch Government Gazette. Order on the prevention, control and monitoring of infectious animal diseases, zoonoses and TSEs (TRCJZ/2005/1411) [in Dutch]. 2005;120:17 [cited 2020 Mar 25]. https:/ / zoek.officielebekendmakingen.nl/ stcrt-2005-120-p17-SC70318.html 
19. Alton GG, Jones LM, Angus RD, Verger JM. Techniques for the brucellosis laboratory. Paris: Institut national de la recherche agronomique; 1988. p. 171-2.

20. World Organisation for Animal Health. Brucellosis. In: Manual of diagnostic tests and vaccines for terrestrial animals. 2018 [cited 2020 Mar 25]. https:/ / www.oie.int/ fileadmin/Home/eng/Health_standards/tahm/3.01.04_ BRUCELLOSIS.pdf

21. Kroese MV, Beckers L, Bisselink YJWM, Brasseur S, van Tulden PW, Koene MGJ, et al. Brucella pinnipedialis in grey seals (Halichoerus grypus) and harbor seals (Phoca vitulina) in the Netherlands. J Wildl Dis. 2018;54:439-49. https://doi.org/10.7589/2017-05-097

22. Maio E, Begeman L, Bisselink $Y$, van Tulden $P$, Wiersma L, Hiemstra S, et al. Identification and typing of Brucella spp. in stranded harbour porpoises (Phocoena phocoena) on the Dutch coast. Vet Microbiol. 2014;173:118-24. https:/ / doi.org/ 10.1016/j.vetmic.2014.07.010

23. Simpson JT, Wong K, Jackman SD, Schein JE, Jones SJM, Birol I. ABySS: a parallel assembler for short read sequence data. Genome Res. 2009;19:1117-23. https:/ / doi.org/ 10.1101/gr.089532.108

24. Milne I, Stephen G, Bayer M, Cock PJA, Pritchard L, Cardle L, et al. Using Tablet for visual exploration of second-generation sequencing data. Brief Bioinform. 2013;14:193-202. https://doi.org/10.1093/bib/bbs012

25. Al Dahouk S, Flèche PL, Nöckler K, Jacques I, Grayon M, Scholz HC, et al. Evaluation of Brucella MLVA typing for human brucellosis. J Microbiol Methods. 2007;69:137-45. https://doi.org/10.1016/j.mimet.2006.12.015

26. Grissa I, Bouchon P, Pourcel C, Vergnaud G. On-line resources for bacterial micro-evolution studies using MLVA or CRISPR typing. Biochimie. 2008;90:660-8. https:/ / doi.org/10.1016/j.biochi.2007.07.014

27. Whatmore AM, Perrett LL, MacMillan AP. Characterisation of the genetic diversity of Brucella by multilocus sequencing. BMC Microbiol. 2007;7:34. https:/ / doi.org/10.1186/ 1471-2180-7-34

28. Jolley KA, Bray JE, Maiden MCJ. Open-access bacterial population genomics: BIGSdb software, the PubMLST.org website and their applications. Wellcome Open Res. 2018;3:124. https://doi.org/10.12688/wellcomeopenres.14826.1

29. Gyuranecz M, Rannals BD, Allen CA, Jánosi S, Keim PS, Foster JT. Within-host evolution of Brucella canis during a canine brucellosis outbreak in a kennel. BMC Vet Res. 2013;9:76. https:/ / doi.org/10.1186/1746-6148-9-76

30. Yang Y, Wang Y, Poulsen E, Ransburgh R, Liu X, An B, et al. Genotyping Brucella canis isolates using a highly discriminatory multilocus variable-number tandemrepeat analysis (MLVA) assay. Sci Rep. 2017;7:1067. https:/ / doi.org/10.1038/s41598-017-01114-7

31. Taleski V, Zerva L, Kantardjiev T, Cvetnic Z, Erski-Biljic M, Nikolovski B, et al. An overview of the epidemiology and epizootology of brucellosis in selected countries of Central and Southeast Europe. Vet Microbiol. 2002;90:147-55. https:/ / doi.org/10.1016/ S0378-1135(02)00250-X

32. Tcherneva E, Rijpens N, Naydensky C, Herman L. Repetitive element sequence based polymerase chain reaction for typing of Brucella strains. Vet Microbiol. 1996;51:169-78. https://doi.org/10.1016/0378-1135(96) 00036-3

33. Fretin D, Whatmore AM, Al Dahouk S, Neubauer H, Garin-Bastuji B, Albert D, et al. Brucella suis identification and biovar typing by real-time PCR. Vet Microbiol.2008; 131:376-85. https:// doi.org/10.1016/j.vetmic. 2008.04.003

34. Greene CE, Carmichael LE. Canine brucellosis. In: Greene CE, editor. Infectious diseases of the dog and cat. 4th ed. Philadelphia: Elsevier Health Sciences; 2011. p. 398-411.

35. National Institute for Public Health and the Environment, National Coordination Centre for Communicable Disease Control. Guideline brucellosis [in Dutch]. 2007 [cited 2019 Jun 13]. https:/ / lci.rivm.nl/richtlijnen/brucellose

Address for correspondence: Els M. Broens, Department of Biomolecular Health Sciences, Faculty of Veterinary Medicine, Utrecht University, Yalelaan 1, 3584 TD, Utrecht, the Netherlands; email: e.m.broens@uu.nl 